\title{
Percepção do Centro para Criança e Adolescentes na visão de seus cuidadores
}

\section{Perception of the Center for Children and Adolescents in the view of their caregivers}

\author{
Adriano Francisco de Oliveira \\ Universidade de São Paulo (USP) \\ E-mail: adrianodefo@usp.br
}

Resumo: Objetivou-se através deste estudo compreender a percepção que cuidadores possuem sobre o convívio de seus entes no Centro para Criança e Adolescentes. Buscou-se através deste estudo averiguar as motivações para inscrição no CCA e as possíveis alterações no relacionamento interpessoal, no desempenho escolar, na alimentação e na prática esportiva. $\mathrm{O}$ método utilizado foi uma pesquisa quantitativa, tendo como instrumento um questionário estruturado com respostas alternativas. Percebeu-se através da análise que houve melhoras no que diz respeito à vida acadêmica, esportiva, alimentação e melhora do relacionamento com o grupo familiar. É possível concluir através dos dados analisados a necessidade de ampliação do número de CCAs na cidade, tendo em vista que o equipamento além de promover a proteção social como the é esperado como função prioritária produz ainda melhorias em diversos aspectos da vida dos usuários e consequentemente de seus cuidadores.

Palavras-Chave: Políticas Públicas; Sociedade Civil; Movimentos Sociais; Assistência Social.

\begin{abstract}
The objective of this study was to understand the perception that caregivers have about the living of their relatives in the Center for Children and Adolescents. The aim of this study was to investigate the motivations for enrollment in the CCA and possible changes in interpersonal relationships, school performance, nutrition and sports practice. The method used was semi-structured research. It was noticed through the analysis that there were improvements regarding academic life, sports, nutrition and improvement of the relationship with the family group. It is possible to conclude from the analyzed data the need to increase the number of CCAs in the city, considering that the equipment besides promoting social protection as it is expected as a priority function still produces improvements in several aspects of the life of the users and consequently of Their caregivers.
\end{abstract}

Keywords: Public Policies; Civil Society; Social Movements; Social Assistance. 
OLIVEIRA, Adriano Francisco de. Percepção do Centro para Criança e Adolescentes na visão de seus cuidadores

\section{Estado e Proteção social}

Para bem compreender a relação entre Estado e proteção social, torna-se importante ter como referência as diferenças conceituais entre os dois termos, o que culminara em distintas intervenções e, consequentemente, em uma forma de proteção plenamente eficaz ou não. Como bem demonstrou Hofling (2001), Estado e governo não significam necessariamente a mesma coisa. Para ele, pode-se considerar o Estado como um conjunto de instituições permanentes como órgãos legislativos, tribunais, exército e outras que não formam um bloco monolítico necessariamente que possibilitam a ação do governo; e governo, como o conjunto de programas e projetos que parte da sociedade (políticos, técnicos, organismos da sociedade civil e outros) propõe para a sociedade como um todo, configurando-se a orientação política de um determinado governo que assume e desempenha. Vale ainda destacar o conceito de políticas públicas utilizado por Saraiva e Ferrarezi (2006) que a define como como um fluxo de decisões públicas, orientando a manter o equilíbrio social ou a introduzir desiquilíbrios destinado a modificar essa realidade.

Deste modo, é possível com tais conceitualizações se aproximar do argumento de Hofling (2001), de que as ações que sustentam as políticas públicas ou programas adotados, ou seja, distintas visões de sociedade e de Estado podem gerar intervenções diferentes. Por tal motivo, se faz necessário uma participação ativa da sociedade civil nas políticas públicas, desde o planejamento até sua execução, passando pela plena participação que contribuem na formação de ideias e valores que possam nortear as noções que fundamentam as ações tanto do governo quanto do próprio Estado.

\subsection{A proteção à criança pequena}

No Brasil a pobreza como questão social de Estado tem seus primeiros registros no início do século XX, entendida pela classe política da época como um problema de moral e higiene. Tal concepção, entre outras, possibilitaram surgir em solo brasileiro e de forma especifica na cidade de São Paulo, inúmeros programas sociais na cidade que visavam à garantia da proteção da população atendida e, em alguns casos, até mesmo a remediação. Desde a chamada Casa do Expostos em 1874, asilos infantis, jardins de infância, casas maternais e até mesmo as creches,

Revista Brasileira de Políticas Públicas e Internacionais, v. 04, n. 02, novembro/2019, pp. 74-90. 
OLIVEIRA, Adriano Francisco de. Percepção do Centro para Criança e Adolescentes na visão de seus cuidadores

percebe-se inúmeras tendências no trabalho de proteção e assistência social prestado, embora alguns, como o caso da creche, já não faça mais parte da rede de assistência, passando a ser concebido como atividade educacional. Era um período em que a questão social tornou-se relevante no cenário político em decorrência da organização dos trabalhadores da indústria. De acordo com Martins e Brito (2001) apud Benelli e Rosa (2011) ao longo do século XX, as políticas públicas buscaram criar medidas sistemáticas de intervenção, visando recuperar e reintegrar os "menores delinquentes" à vida social, sobretudo por meio dos reformatórios em regime fechado. Os autores continuam:

No início do século XX, com as mudanças sociais e políticas, o Estado começa a ter uma maior participação nos cuidados com a infância: aparece o termo "menor", remetendo a uma noção de menoridade desses atores sociais ligada a questões de criminalidade. Eles passam a ser percebidos a partir da noção de periculosidade, e, com uma preocupação acerca de sua gestão e tutela, instituições de internação surgem para ligá-los a aparelhos de correção, buscando seu enquadramento, controle e normalização (Benelli \& Rosa, 2011, p. 546).

Neste sentido, grande importância possui a constituição de 1988 para a formulação do que seria um conceito novo e até mesmo revolucionário da proteção social como política pública:

Portanto, trata-se de um pacto que inclui a universalidade da proteção social na seguridade social. $\mathrm{E}$ até a promulgação da $\mathrm{CF} / 88$ não se dispunha de uma concepção nacional sobre assistência social, embora já existisse há mais de dez anos uma Secretaria Nacional de Assistência Social instalada no Ministério da Previdência e Assistência Social (Sposati, 2009, p. 15).

Com a inauguração de nossa forma de pensar a política social no Brasil é que os projetos passam a existir seguindo a conformidade e as diretrizes de uma política pública minimamente organizada e longa das concepções anterior que, além de assistencialistas, tendiam muitas vezes em ver a questão criança e também do adolescente como problema. Surge também neste contexto e em nível nacional o Estatuto da Criança e do Adolescente

Revista Brasileira de Políticas Públicas e Internacionais, v. 04, n. 02, novembro/2019, pp. 74-90. 
OLIVEIRA, Adriano Francisco de. Percepção do Centro para Criança e Adolescentes na visão de seus cuidadores

(ECA) promulgado pela lei 8.069 de 13 de julho de 1990, contribuindo para que a sociedade perceba a proteção à criança não apenas como algo institucional

No que diz respeito a cidade de São Paulo, entre os inúmeros projetos que foram se iniciando, torna-se útil para bem compreender a presente analise, mencionar ainda a inauguração dos chamados Parque Infantis (PI), fundado em 1930 e ligado ao departamento de cultura, do qual fazia parte Mario de Andrade. Através do PI, inicia-se uma fase de atenção que englobava em seu início a faixa etária dos três aos 12 anos de idade.

Já na década de 70, surgiu na cidade um novo projeto, denominado de Orientação Socioeducativa ao Menor do projeto OSEM, criado na Coordenadoria do Bem-Estar Social, COBES, a partir da análise das experiências do projeto de "atendimento ao Menor Trabalhador de rua", em 1975, a diferença fundamental deste projeto é que ele passaria a atender a chamada clientela próximo a residência. Contudo, já em 1979 já se percebia a necessidade de revisão e ampliação de atendimento do projeto, já que havia uma demanda de aproximadamente trezentos e cinquenta mil menores na faixa de 7 a 14 anos, que vinham de famílias que recebiam até 3,75 salários mínimos e que viviam em precárias condições.

De acordo com Romero (2012), historicamente os CCAs já tiveram outros nomes como: orientação socioeducativa ao menor (OSEM), Centro da Juventude (CJ), Espaço Gente Jovem (EGJ), núcleo sócio educativo (NSE). É a partir das diretrizes do Ministério do Desenvolvimento Social, da criação do Ministério do Desenvolvimento Social e consequentemente da criação da LOAS (Lei Orgânica da Assistência Social) que se estabelece na cidade de São Paulo a tipificação do CCA - Centro para Criança e Adolescente -, sendo que no ano de 2013, houve uma alteração na nomenclatura do serviço, passando a ser denominado de SCFV CCA-Serviço de Convivência e Fortalecimento de Vínculo, na modalidade CCA.

\subsection{O Centro para Criança e Adolescente}

Oferecer proteção social básica a crianças a adolescentes tem sido um dos principais objetivos do CCA - Centro para Crianças e Adolescentes da cidade de São Paulo. Os atendimentos são voltados a crianças de 6 a 11 anos e 11 meses e adolescentes de 12 a 14 anos e 11 meses. Trata-se de um projeto vinculado à Secretaria de Assistência Social da cidade e que

Revista Brasileira de Políticas Públicas e Internacionais, v. 04, n. 02, novembro/2019, pp. 74-90. 
OLIVEIRA, Adriano Francisco de. Percepção do Centro para Criança e Adolescentes na visão de seus cuidadores

possuí hoje um total de 69.955 matriculados em 475 núcleos distribuídos pelo município (SMADS, 2014). O público alvo prioritário do CCA são usuários que estejam em condições de vulnerabilidade social.

De acordo com Romero 2012, a partir dos preceitos do ECA, os CCAs se constituem num tipo de serviço que considera crianças e adolescente enquanto sujeito de direitos, na medida em que reconhecem sua condição peculiar de pessoas em desenvolvimento, buscando oferecer-lhes proteção integral por meios de ações intersetoriais integradas com o poder público.

O projeto busca para chegar a tal finalidade favorecer a interlocução com o território a fim de inserir os usuários nos serviços públicos disponíveis. Objetiva-se também a realização de ações voltadas para a comunidade e para as famílias dos usuários. Pode-se dizer que o CCA busca ser no território um espaço de convívio para a faixa etária indicada sem que para isso seja necessário sair do território. Em sua pesquisa, Romero (2012) chega a uma conclusão de grande impacto sobre o setor e que pode ser considerada controversa em muitos aspectos: diferente do CRAS, no CCA os problemas locais são levados para o serviço e a equipe busca dar uma solução também local. É principalmente neste sentido que o CCA é mais enraizado ou territorializado que o CRAS (Centro de Referência Assistência Social).

Essa conclusão obtida por Romero (2012) não é a preconizada pelas normativas que regem tanto os objetivos do CRASs quanto do CCA, mas que vem ocorrendo em diversas regiões do país.

\subsection{A relação com as $O N G S$}

Dos núcleos de CCA existentes na cidade, 100\% são gerenciados por Organizações Não Governamentais por meio de convênios firmados entre essas organizações e a própria Secretaria de Desenvolvimento e Assistência Social. Vale ressaltar que das 499 ONGs existentes na cidade, 373 possuem algum tipo de convenio com a Secretaria. Trata-se de um processo que se inicia com edital de chamamento público que colhe proposta de organizações interessadas e conclui-se com uma audiência pública entre as partes, onde posteriormente o comitê selecionador, formado por técnicos da própria SMADS (Secretaria Municipal de

Revista Brasileira de Políticas Públicas e Internacionais, v. 04, n. 02, novembro/2019, pp. 74-90. 
OLIVEIRA, Adriano Francisco de. Percepção do Centro para Criança e Adolescentes na visão de seus cuidadores

Assistência e Desenvolvimento Social), divulga em diário oficial as considerações, conteúdo das propostas e o resultado, ou seja, a organização selecionada para gerenciar o serviço.

Uma importante característica do CCA é o fato de servir como opção para o turno escolar, já que as crianças o frequentam no chamado contraturno, ou seja, os que estudam de manhã costumam frequentar o núcleo à tarde. Tal característica, faz com que muitas vezes a criança fique em tempo integral fora de sua residência.

Entretanto, parece ser de conhecimento comum o que os familiares esperam de uma escola, mas quanto a um CCA? Tal questionamento me inquietou. Sabemos o que os pais esperam do núcleo por meio de reuniões realizadas periodicamente, mas interessou-nos compreender através de uma pesquisa metodológica o que essas famílias têm percebido dos seus que frequentam o Centro para Criança e Adolescentes. O que tem acontecido com essas crianças depois de matriculadas? Houve alterações na convivência famílias, na vida escolar, no comportamento com os amigos, na pratica de esportes, na alimentação e na relação com os pais? Por qual motivo os familiares resolveram cadastrá-los? Tal questionamento é importante para que se compreendam as motivações dos cuidadores para a conclusão de seus filhos e familiares nos núcleos mencionados.

\section{Objetivos do estudo}

Buscou-se através deste estudo, compreender o olhar que estes cuidadores possuem para o serviço oferecido. Objetiva-se revelar fatores comportamentais dos usuários a partir da visão dos pais ou responsáveis pelos mesmos.

O distrito escolhido foi o Jardim Helena, Zona Leste da cidade de São Paulo. Trata-se de uma região classificada como tendo um alto índice de vulnerabilidade social segundo o mapa Vulnerabilidade Social. O distrito possui 135.043 mil habitantes segundos dados do IBGE, sendo que a população entre 6 a 14 anos e 11 meses, faixa etária do CCA, soma um total de 24.670 (14.139 crianças e 24.670 adolescentes). A área total do Jardim helena é de 7,5 Km 2. O distrito possui 3 CCAs, que juntos atendem em média 540 crianças e adolescentes.

Foi realizada uma pesquisa quantitativa, junto a 159 pais ou responsáveis de crianças e adolescentes. As entrevistas foram realizadas em dois CCAs dentro do distrito. Foram

Revista Brasileira de Políticas Públicas e Internacionais, v. 04, n. 02, novembro/2019, pp. 74-90. 
OLIVEIRA, Adriano Francisco de. Percepção do Centro para Criança e Adolescentes na visão de seus cuidadores

escolhidos estes dois equipamentos e nesta região porque realizamos trabalhos neles, o que facilitou a aproximação e a coleta de dados. Os cuidadores que participaram, foram convidados para reunião bimestral dos CCAs, e os dados foram coletados por meio de um questionário estruturado com respostas alternativas. Os resultados contidos foram extraídos a partir do público alvo em sua maioria de seis a onze anos e onze meses.

\section{Resultados e Discussão}

Buscando compreender o relacionamento familiar segundo a percepção dos responsáveis, após o ingresso no CCA, obtivemos o seguinte gráfico:

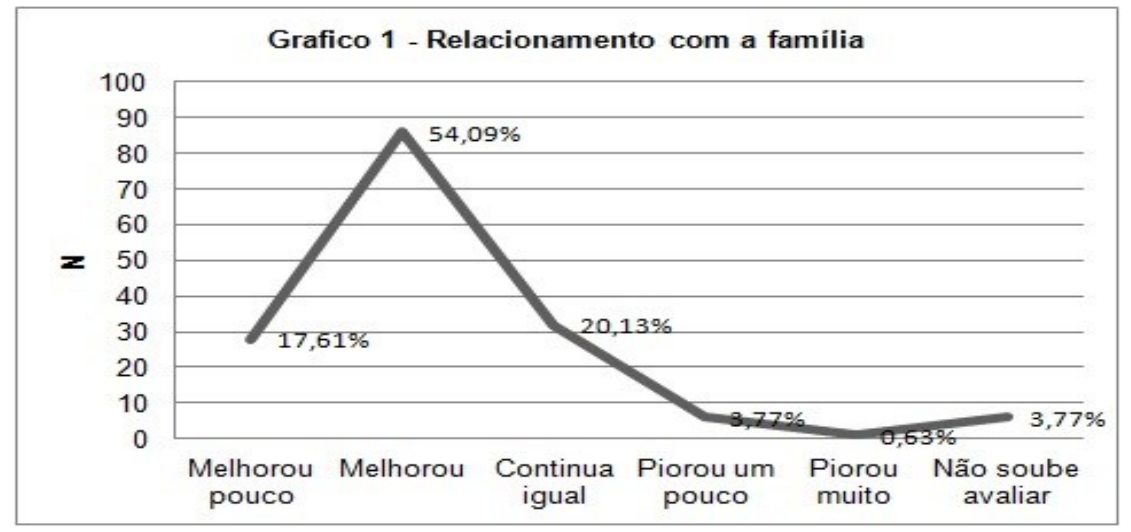

Fonte: Elaboração dos autores.

No Gráfico 1, é possível observar que de acordo com os pais houve considerável melhora do relacionamento do filho (a) com relação a todo o grupo familiar. Dos entrevistados, $17,61 \%$ indicam que este relacionamento melhorou pouco, 54,09 \% que melhorou e para $20,13 \%$ continua igual. Os que indicam que piorou um pouco foram $3,77 \%$, piorou muito $0,63 \%$ e $3,77 \%$ não souberam avaliar.

A família é um dos eixos fundamentais de organização e desenvolvimento da vida das pessoas. É o primeiro ambiente de socialização e a primeira mediadora das influências culturais, modelos e padrões de comportamento, importante instituição formadora de valores, ideias, crenças e significados existentes na sociedade, e vem sendo considerada importante no sistema social, como um espaço privilegiado de atenção das políticas públicas (Goldani, 2002; Silva \& Fonseca, 2007; Witter \& Silva, 2011). Possui um papel essencial junto ao Revista Brasileira de Políticas Públicas e Internacionais, v. 04, n. 02, novembro/2019, pp. 74-90. 
OLIVEIRA, Adriano Francisco de. Percepção do Centro para Criança e Adolescentes na visão de seus cuidadores

desenvolvimento da socialização, principalmente em relação às crianças e adolescentes, pois é a mediadora que dará um modelo de relação com o mundo ensinando a respeitar e introjetar regras, limites e proibições necessárias à vida em sociedade (Brasil, 2006).

Entende-se por família a definição proposta pelo Plano de Promoção, Proteção e Defesa do Direito de Crianças e Adolescentes à Convivência Familiar e Comunitária (PNCFC), que define família como:

Um grupo de pessoas que são unidas por laços de consanguinidade, de aliança e de afinidade. Esses laços são constituídos de representações, práticas e relações de obrigações mútuas. Por sua vez, estas obrigações são organizadas de acordo com a faixa etária, as relações de geração e de gênero, que definem o status da pessoa dentro do sistema de relações familiares (Brasil, 2006, p. 24).

Na mesma perspectiva da PNCFC, a Política Nacional de Assistência Social (PNAS) também objetiva o desenvolvimento familiar, de acordo com essa Política, nos sistemas de bem-estar social as famílias têm sido apresentadas como importantes atores, pois são decisivas na garantia de qualidade de vida de seus membros e fonte de suporte material e afetivo (Goldani, 2002 e PNAS, 2004).

A centralidade da família é garantida na medida em que a assistência social, com base em indicadores das necessidades familiares, desenvolve uma política de cunho universalista que, em conjunto com outras políticas, valoriza a convivência familiar e comunitária. Preferencialmente as políticas sociais devem ser públicas, evitando-se a fragmentação das ações e garantindo-se o acesso e a qualidade dos serviços para todos os cidadãos.

As políticas públicas visam responder a demandas, principalmente de setores marginalizados da sociedade, considerados como vulneráveis (Teixeira, 2002). É o Estado implantando projetos de governo, através de programas, de ações voltadas para setores específicos da sociedade, caso das famílias de baixa renda (Hofling, 2001).

Nesse sentido, a melhora no relacionamento apontado pelas famílias dos usuários do CCA, conforme os dados demonstrados no Gráfico 1, pode ser compreendida como uma

Revista Brasileira de Políticas Públicas e Internacionais, v. 04, n. 02, novembro/2019, pp. 74-90. 
OLIVEIRA, Adriano Francisco de. Percepção do Centro para Criança e Adolescentes na visão de seus cuidadores

política de apoio importante para organização familiar. Evidentemente que existem outras variáveis que não são escopo deste estudo que também precisam ser consideradas.

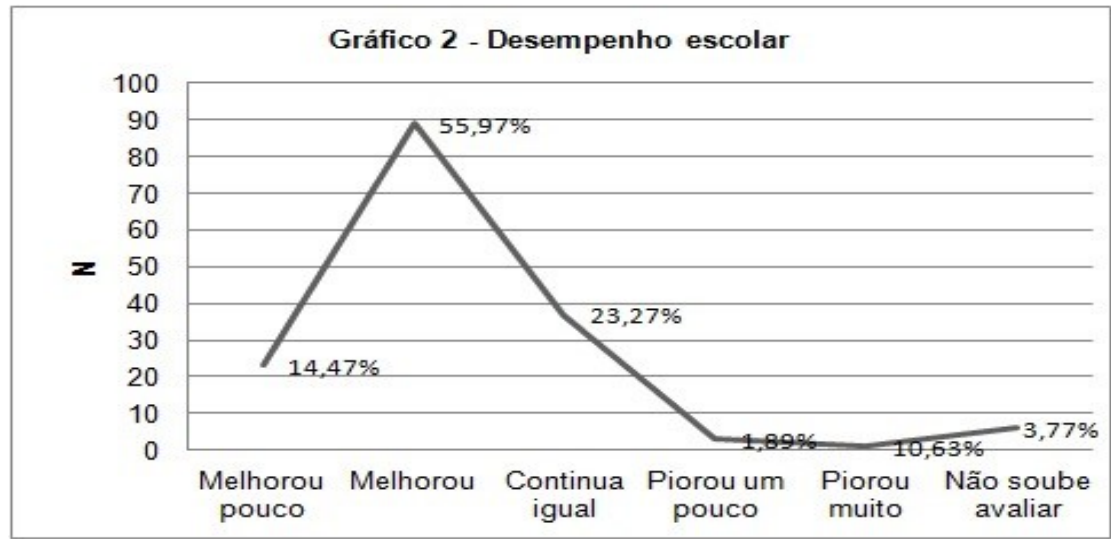

Fonte: Elaboração dos autores.

Conforme os dados do Gráfico 2, 14,74\% dos usuários melhoraram um pouco em relação ao desempenho escolar, 55,97\% tiveram melhora, 23,27\% continuam igual, 1,89\% pioram um pouco e $3,77 \%$ não souberam responder. A melhora do desempenho escolar chamou atenção neste estudo, pois embora este não seja um objetivo explícito do CCA ele aconteceu de forma espontânea, já que há pouco espaço para as chamadas atividades escolares dentro do serviço. Os que melhoraram pouco ou que simplesmente melhoraram o desempenho escolar desde que entraram no CCA somam um total de 70,44 \%.

Trata-se de um dado extremamente importante no sentido de analisar as estratégias utilizadas que estão além do âmbito escolar e que termina por ter ressonância na vida acadêmica, o que pode sugerir a importância da integração das ações educativas, escolares, esportivas, culturais e até mesmo sociais etc. Há ainda uma visão amplamente divulgada principalmente nos setores ligados a educação evidenciado por Romero (2012) de que quando a educação ocorre fora da escola, alguns autores têm trabalhado com as noções de educação não formal ou educação informal.

Revista Brasileira de Políticas Públicas e Internacionais, v. 04, n. 02, novembro/2019, pp. 74-90. 
OLIVEIRA, Adriano Francisco de. Percepção do Centro para Criança e Adolescentes na visão de seus cuidadores

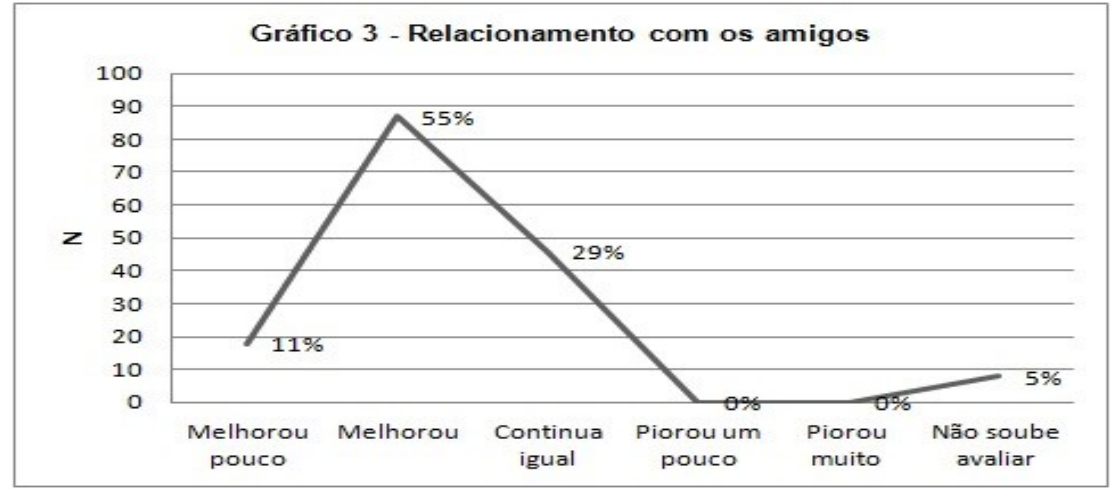

Fonte: Elaboração dos autores.

De acordo com os cuidadores, houve uma melhora para $55 \%$ dos entrevistados no relacionamento com relação a outros amigos, sendo que outros 11\% indicam que este relacionamento melhorou pouco e $29 \%$ dizem que continua igual. Do total pesquisado, 5\% não souberam avaliar e o número dos que indicam que houve piora não chega a $1 \%$. Estes números demonstram a capacidade que o serviço pode oferecer no sentido de integração e convivência, contribuindo para diminuição de conflitos, melhor vivencia com diferenças e maior harmonização das relações.

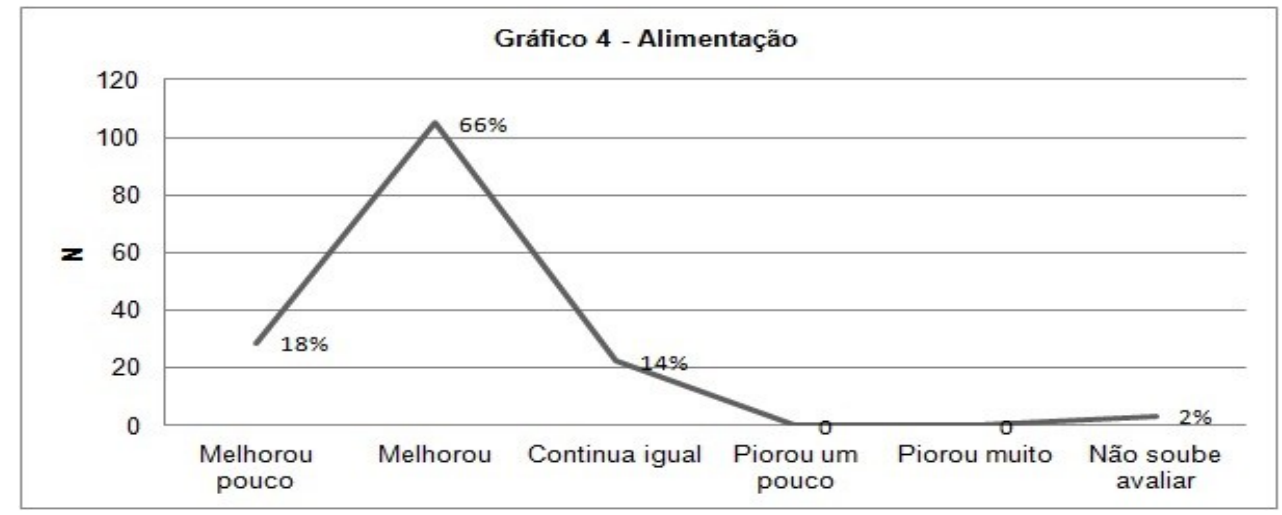

Fonte: Elaboração dos autores.

Houve melhora na alimentação dos filhos para 84\% das famílias analisadas, sendo que dessas $66 \%$ indicam que melhorou e 18\% que melhorou pouco. Deste total, $2 \%$ não souberam avaliar. Em termo de nutrição infantil, diversos estudos tem demonstrado os benefícios de uma alimentação equilibrada nessa faixa etária, inclusive no combate a chamada obesidade infantil como demonstrou Mello, Luft e Meye (2004). Sobre os adolescentes, Sichieri (2000)

Revista Brasileira de Políticas Públicas e Internacionais, v. 04, n. 02, novembro/2019, pp. 74-90. 
OLIVEIRA, Adriano Francisco de. Percepção do Centro para Criança e Adolescentes na visão de seus cuidadores

demonstram que se trata de uma faixa etária particularmente influenciáveis em seu estilo de vida e deveriam ser prioritariamente contemplados em programas de saúde coletiva. Vários estudos indicam que a manutenção de um peso considerado adequado entre meninas adolescentes se faz através de práticas alimentares inadequadas, como omitir refeições, e que o consumo de nutrientes como cálcio e ferro é inadequado neste grupo.

É importante ressaltar que os grupos em questão estão localizados em uma região de alta vulnerabilidade social onde um dos mais problemas apontados por este índice é a dificuldade no acesso a alimentação com valores nutritivos adequados. Fica evidente que a alimentação dentro do CCA favoreceu de forma consistente para a melhora alimentar dos usuários o que pode evitar eventuais problemas de saúde e ainda favorecer um saudável crescimento em uma fase onde a nutrição torna-se essencial.

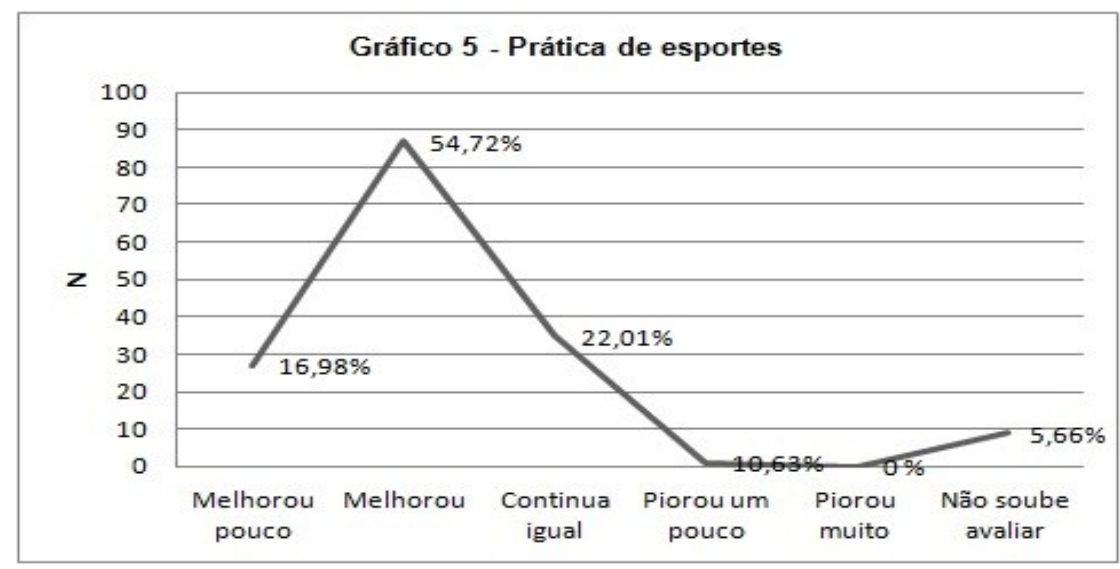

Fonte: Elaboração dos autores.

Sobre as atividades físicas, percebe-se na literatura diversos estudos que apontam seus benefícios. Lazolli (1998) demonstrou que em crianças e adolescentes, um maior nível de atividade física contribui para melhorar o perfil lipídico e metabólico e reduzir a prevalência de obesidade. Ainda, é mais provável que uma criança fisicamente ativa se torne um adulto também ativo. Em consequência, do ponto de vista de saúde pública e medicina preventiva, promover a atividade física na infância e na adolescência significa estabelecer uma base sólida para a redução da prevalência do sedentarismo na idade adulta, contribuindo desta forma para uma melhor qualidade de vida.

Revista Brasileira de Políticas Públicas e Internacionais, v. 04, n. 02, novembro/2019, pp. 74-90. 
OLIVEIRA, Adriano Francisco de. Percepção do Centro para Criança e Adolescentes na visão de seus cuidadores

Entretanto, no distrito analisado o acesso a pratica esportiva está quase que restrito a escola, existe poucas quadras públicas, com serias dificuldades de acesso devido principalmente a ocupação de usuários de entorpecentes. A atividade física nessa faixa etária é importante por criar o hábito e o interesse pela atividade, e não treinar visando desempenho. Dessa forma, deve-se priorizar a inclusão da atividade física no cotidiano e valorizar a educação física escolar que estimule a prática de atividade física para toda a vida, de forma agradável e prazerosa, integrando as crianças e não discriminando os menos aptos (Lazolli, 1998).

Nesta pesquisa, a pratica de esportes foi outro item com melhora significativa, $71,69 \%$ dos entrevistados indicam que seus filhos tiveram melhoras ou poucas melhoras com relação a pratica esportiva, 22,01\% indicam que continua igual e 5,66\% não souberam avaliar. A pratica esportiva é um item de extrema importância para o desenvolvimento físico e intelectual das crianças e adolescentes e a melhora em sua pratica pode significar também um adulto mais saudável.

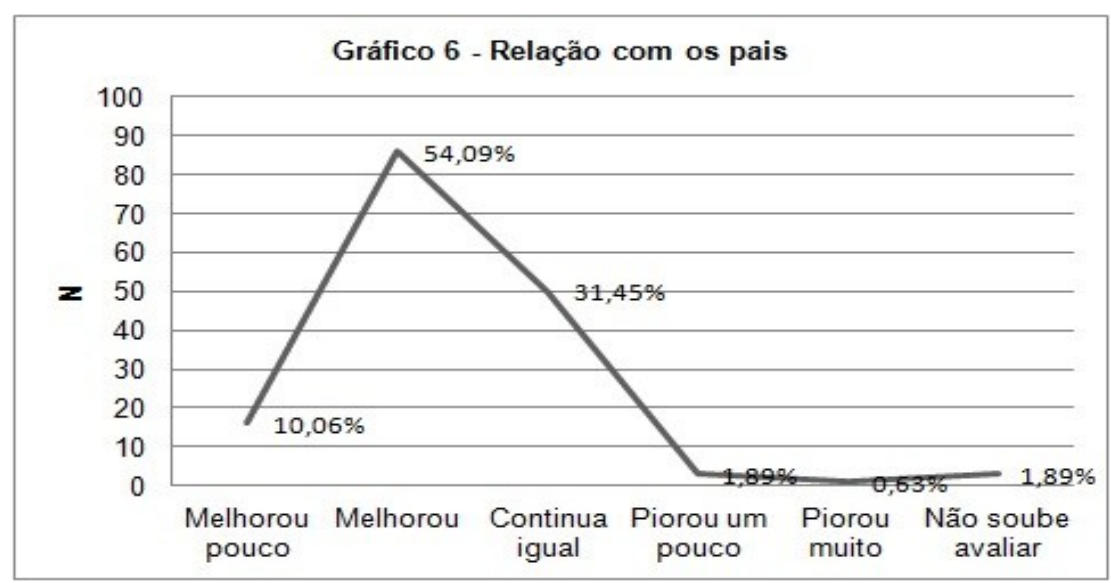

Fonte: Elaboração dos autores.

Se no primeiro gráfico o objetivo era perceber se houve melhora com relação ao grupo familiar, neste item o objetivo era averiguar se houve melhora de comportamento com relação aos pais. Através das entrevistas, percebeu-se que 54,08\% indicaram que houve melhoras e outros $31,44 \%$ disseram que essas melhoras foram poucas. Ou seja, a participação das

Revista Brasileira de Políticas Públicas e Internacionais, v. 04, n. 02, novembro/2019, pp. 74-90. 
OLIVEIRA, Adriano Francisco de. Percepção do Centro para Criança e Adolescentes na visão de seus cuidadores

atividades do CCA melhorou a relação dos filhos com o grupo familiar conforme descrito no Gráfico 1 e de forma específica foi percebida uma melhora também com relação aos pais.

De acordo com Densen (2014), o desenvolvimento da criança vem sendo também interpretado como intervindo nas interações e relações familiares, criando não só uma dinâmica familiar específica aos diversos pontos críticos, como também desencadeando mudanças familiares que, por sua vez, podem influenciar o próprio curso de desenvolvimento da criança (Kreppner, Paulsen \& Schuetze, 1982).Por tal motivo, destaca-se o resultado obtido neste gráfico demonstrando o alcance do serviço no que diz respeito às questões familiares.

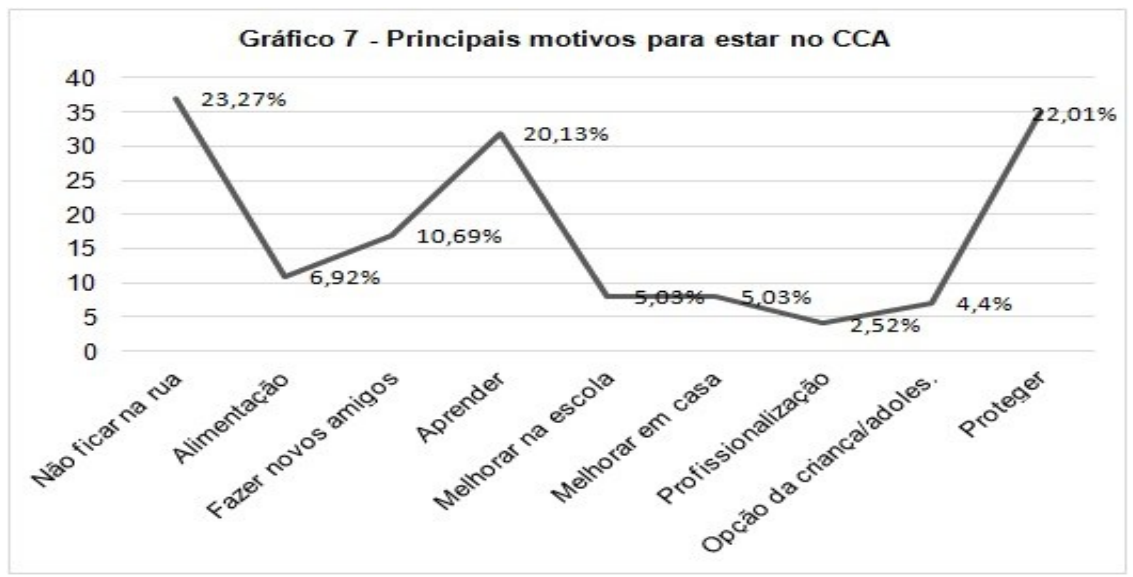

Fonte: Elaboração dos autores.

No Gráfico 7, foi possível analisar os principais motivos pelos quais as famílias resolveram inscrever as crianças em um CCA dentro do distrito Jardim Helena.

É possível notar que 23, 27\% dos entrevistados inscreveram seus filhos no CCA justamente para que os mesmos não fiquem na rua, o que pode estar aliado ao sinônimo que tem hoje a rua principalmente no distrito analisado, onde os índices de vulnerabilidade social são considerados muito alto, e a rua torna-se o local da insegurança. Protege-lo socialmente foi à segunda opção o que corresponde a 22,01\% dos entrevistados, essa opção inclusive coincide com um dos principais objetivos do CCA em termos de edital que é a garantia dos direitos das crianças e adolescentes e oferecer a ambos a necessária proteção social.

Há muita preocupação com aqueles que ficam na rua e que estariam fazendo "nada" ou aprendendo o que "não presta". Entretanto, é cabível a discussão sobre dados apontados por

Revista Brasileira de Políticas Públicas e Internacionais, v. 04, n. 02, novembro/2019, pp. 74-90. 
OLIVEIRA, Adriano Francisco de. Percepção do Centro para Criança e Adolescentes na visão de seus cuidadores

alguns conselhos tutelares do Brasil e demonstrados no estudo de Costa et al (2007) e Baron (2008) de que a negligencia está entre as principais queixas registradas no conselho. No primeiro estudo em questão, 78\% das ocorrências ocorreram em domicilio e no segundo, chega-se a 44,1\%. As diferenças significativas entres os dois casos se dá principalmente devido as diferenças que cada pesquisa seguiu na categorização dos dados coletados. $\mathrm{O}$ que fica evidente como demonstrou Reichenheim (1999) é que a maioria dos casos de violência contra a criança acontece em casa. Outra questão que é importante de consideração é a subnotificação no caso dos conselhos, por ser ainda uma realidade brasileira.

Em terceiro lugar no que ser refere à motivação dos pais, constatou-se que $20 \%$ dos responsáveis indicaram como principal motivo aprender. Esse dado demonstra que os responsáveis percebem com clareza a diferença entre os processos de aprendizagem que são realizados por meio das atividades socioeducacionais e o ensino formal realizado dentro da escola, pois somente $5 \%$ dos entrevistados apontou como expectativa que as crianças/adolescentes apresentem melhora no desempenho escolar.

Como quarta opção (10\%) apontada pelos entrevistados, aparece como motivação fazer novos amigos, o que vai de encontro com a caracterização do serviço que pretende ser um espaço de convivência a partir dos interesses e demandas dos usuários (SMADS, 2018).

Algumas questões que aparecem pouco como aprender uma profissão para que o filho melhore na escola ou porque o mesmo insistiu reforça a ideia de que as famílias esperam que o CCA seja antes de qualquer outra coisa, um local de proteção e convívio, não colocando sobre o serviço expectativas profissionalizantes ou até mesmo escolares, mesmo a melhora acadêmica ter ocorrido na maioria dos usuários analisados.

\section{Conclusões}

De acordo com os dados levantados, foi possível concluir que a participação das atividades no Centro para Criança e Adolescentes dentro do distrito Jardim Helena, provocou de acordo com os cuidadores entrevistados, um melhor relacionamento com o grupo familiar, melhora no desempenho escolar, no relacionamento com os amigos, na alimentação, na pratica de esportes e no relacionamento com os pais e/ ou responsáveis.

Revista Brasileira de Políticas Públicas e Internacionais, v. 04, n. 02, novembro/2019, pp. 74-90. 
OLIVEIRA, Adriano Francisco de. Percepção do Centro para Criança e Adolescentes na visão de seus cuidadores

Observou-se ainda que os principais motivos para a inscrição das Crianças e Adolescentes nos CCAs são tira-los da rua, protegê-los socialmente e para que possam aprender algo.

Conclui-se que o projeto provocou na visão dos cuidadores, alterações importantes em diversos aspectos da vida dos usuários. Outros estudos podem preocupar-se com a análise especifica de alguns dos itens aqui levantados, o que pode ajudar a compreendê-los com maior profundidade. A percepção dos cuidadores com relação ao CCA está repleta de aspectos positivos onde se evidencia a importância de aumentar este tipo de equipamento na cidade, principalmente nas regiões onde se prevalece a vulnerabilidade social. Conclui-se que o CCA é na percepção dos entrevistados dentro do distrito Jardim Helena um equipamento que contribui de forma efetiva para a proteção social dos seus.

\section{Referências}

Bazon, M. (2008, fevereiro). Violências contra crianças e adolescentes: análise de quatro anos de notificações feitas ao Conselho Tutelar na cidade de Ribeirão Preto, São Paulo, Brasil. Cad. Saúde Pública, Rio de Janeiro, v. 24, n. 2. Recuperado em 26/08/2014, de http://www.scielo.br/scielo.php?script $=$ sci arttext\&pid $=$ S0102-

311X2008000200011\&lng=en\&nrm=iso. Doi: 10.1590/S0102-311X2008000200011.

Benelli, S. J., \& Costa-Rosa, A. da. (2011, dezembro). Para uma crítica da razão socioeducativa em entidades assistenciais. Estud. psicol., Campinas, v. 28, n. 4, 539-563. Recuperado em 16/09/2019, de $\quad$ http://www.scielo.br/scielo.php?script=sci arttext\&pid=S0103166X2011000400014\&lng=en\&nrm=iso. Doi: 10.1590/S0103-166X2011000400014.

Brasil. Ministério do Desenvolvimento Social e Combate à Fome (2006). Norma Operacional Básica do Suas (NOB/Suas). Brasília.

Brasil, Ministério do Desenvolvimento Social e Combate à Fome, Secretaria Nacional de Assistência Social - SNAS (2004). Política Nacional de Assistência Social (PNAS). Norma Operacional Básica -NOB/SUAS. Brasília: SNAS.

Brasil (2006). Plano Nacional de Promoção, Proteção e Defesa do Direito de Crianças e Adolescentes à Convivência Familiar e Comunitária. Brasília.

Revista Brasileira de Políticas Públicas e Internacionais, v. 04, n. 02, novembro/2019, pp. 74-90. 
Cardia, N., \& Shiffer, S. (2002, julho/setembro). Violência e desigualdade social. Revista Ciência e Cultura, São Paulo, 25-31.

Costa, M. C. O. et al (2007, outubro). O perfil da violência contra crianças e adolescentes, segundo registros de Conselhos Tutelares: vítimas, agressores e manifestações de violência. Ciênc. saúde coletiva, Rio de Janeiro, v. 12, n. 5. Recuperado em 26/08/2014, de $\underline{\mathrm{http}} / / / \mathrm{www}$.scielo.br/scielo.php?script $=$ sci arttext\&pid=S1413$\underline{81232007000500010 \& \operatorname{lng}=\mathrm{en} \& \mathrm{nrm}=\mathrm{iso}}$. Doi: 10.1590/S1413-81232007000500010.

Dessen, M. A. (1997, dezembro). Desenvolvimento familiar: transição de um sistema triásico para poliádico. Temas psicol., Ribeirão Preto, v. 5, n. 3. Recuperado em 25/08/2014, de http://pepsic.bvsalud.org/scielo.php?script=sci arttext\&pid=S1413389X1997000300006\&lng=pt\&nrm=iso.

Goldani, A. M. (2002, janeiro/junho). Família, Gênero e políticas públicas: famílias brasileiras nos anos 90 e seus desafios como fator de proteção. Ver. Brás. De Estudos da População. V. 19. $n^{\circ} 1,29-48$.

Höfling, E. de M. (2001, novembro). Estado e políticas (públicas) sociais. Caderno CEDES, Campinas, v. 21, n. 55, 30-41. Recuperado em 21/06/2019, de http://www.scielo.br/pdf/ccedes/v21n55/5539.pdf.

Lazzoli, J. K. et al (1998, agosto). Atividade física e saúde na infância e adolescência. Rev Bras Med. Esporte, Niterói, v. 4, n. 4. Recuperado em 19/08/2014, de http://www.scielo.br/scielo.php?script=sci arttext\&pid=S1517$\underline{86921998000400002 \& \operatorname{lng}=\text { en\&nrm=iso. Doi: } 10.1590 / \mathrm{S} 1517-86921998000400002 .}$

Melo, E. et al (2004). Obesidade Infantil: como podemos ser eficazes? Jornal de Pediatria, Vol. 80, $\mathrm{N}^{\circ} 3$.

Reichenheim, M., Hasselmann, M. H., \& Moraes, C. L. (1999). Consequências da violência familiar na saúde da criança e do adolescente: contribuições para a elaboração de propostas de ação. Ciênc. saúde coletiva, Rio de Janeiro, v. 4, n. 1. Recuperado em 26/08/2014, de http://www.scielo.br/scielo.php?script=sci arttext\&pid=S141381231999000100009\&lng=en\&nrm=iso. Doi: 10.1590/S1413-81231999000100009.

Rodrigues, M. et al (2000, julho/dezembro). A família e sua importância na formação do cidadão. Fam. Saúde Desenv., Curitiba, v.2, n.2, 40-48.

Romero, N. M. (2012). Práticas de educadores como política de assistência social: os Centros para crianças e adolescentes na cidade de São Paulo. (Dissertação de Mestrado) Universidade de São Paulo, Faculdade de Educação, São Paulo.

Revista Brasileira de Políticas Públicas e Internacionais, v. 04, n. 02, novembro/2019, pp. 74-90. 
OLIVEIRA, Adriano Francisco de. Percepção do Centro para Criança e Adolescentes na visão de seus cuidadores

Sichieri, R. et al (2000, junho). Recomendações de alimentação e nutrição saudável para a população brasileira. Arq Bras Endocrinol Metab, São Paulo, v. 44, n. 3. Recuperado em 25/08/2014, de $\quad$ http://www.scielo.br/scielo.php?script=sci arttext\&pid=S000427302000000300007\&lng=en\&nrm=iso. Doi: 10.1590/S0004-27302000000300007.

SMADS - Secretaria Municipal de Assistência e Desenvolvimento Social (2018). Centro para Crianças e Adolescentes (CCA). São Paulo: Secretaria Municipal de Assistência e Desenvolvimento Social $\quad$ (SMADS). de https://www.prefeitura.sp.gov.br/cidade/secretarias/assistencia_social/protecao_social_basica/i ndex.php?p=159208.

Saraiva, E., \& Ferrarezi, E. (2006). Políticas públicas; coletânea. $2^{\circ}$ Vol. Brasília: Escola Nacional de Administração Pública (ENAP).

Sposati, A. (2009). Modelo brasileiro de proteção social não contributiva: concepções fundantes. In: Concepção e gestão da proteção social não contributiva no Brasil. Brasília: Ministério do Desenvolvimento Social e Combate à Fome, UNESCO, pp. 13- 56.

Witter, G. P., \& Silva, J. R. (2011). Família: Conceito, história e papéis. In: Witter, G. P. (Org.). Família e Aprendizagem. Cotia/São Paulo: Ateliê Editorial, pp. 33-54.

Revista Brasileira de Políticas Públicas e Internacionais, v. 04, n. 02, novembro/2019, pp. 74-90. 